УДК 664.8.03

05.00.00 Технические науки

ИССЛЕДОВАНИЕ ВЛИЯНИЯ ОБРАБОТКИ
ФРУКТОВ ЭЛЕКТРОМАГНИТНЫМИ
ПОЛЯМИ КРАЙНЕ НИЗКИХ ЧАСТОТ И
БИОПРЕПАРАТАМИ НА ПОТЕРИ
БИОЛОГИЧЕСКИ АКТИВНЫХ ВЕЩЕСТВ В
ПРОЦЕССЕ ХРАНЕНИЯ

Купин Григорий Анатольевич к.т.н., РИНЦ SPIN-код 1946-6756, kisp@kubannet.ru

Першакова Татьяна Викторовна д.т.н., РИНЦ SPIN-код: 4342-6560, 7999997@inboxru

Горлов Сергей Михайлович к.т.н., РИНЦ SPIN-код 5082-8400 gorlov76@list.ru

Викторова Елена Павловна д.т.н., профессор РИНЦ SPIN-код: 9599-4760 kisp@kubannet.ru

Матвиенко Алина Николаевна РИНЦ SPIN-код 4564-8347, kisp@kubannet.ru

Великанова Елена Васильевна к.т.н., РИНЦ SPIN-код: 9695-7292 kisp@kubannet.ru «Краснодарский научно-исследовательский институт хранения и переработки сельскохозяйственной продукиии» - филиал ФГБНУ "Северо-Кавказский федеральный научный иентр садоводства, виноградарства, виноделия», Россия, 350072, г. Краснодар, ул. Тополиная аллея, $\partial .2$

Известные в настоящее время технологии хранения фруктов, решая актуальные задачи - замедления биохимических процессов, ингибирования синтеза этилена, не обеспечивают в полной мере сохранение качества фруктов в процессе хранения в связи с тем, что не учитывают особенности микрофлоры фруктов и микробиологических процессов, протекающих при хранении. Цель исследования: изучение влияния комплексной обработки фруктов электромагнитными полями крайне низких частот (ЭМП КНЧ) и биопрепаратом «Витаплан» на изменение потерь биологически активных веществ в процессе длительного хранения. Объекты исследования: яблоки сорта Айдаред и груши сорта Конференция, районированные в Краснодарском крае. В процессе
UDC 664.8 .03

Engineering

\section{INVESTIGATION OF THE INFLUENCE OF \\ FRUIT TREATMENT WITH ELECTROMAGNETIC FIELDS OF EXTREMELY LOW FREQUENCY AND BIO- PREPARATIONS ON THE LOSS OF BIOLOGICALLY ACTIVE SUBSTANCES IN THE PROCESS OF STORING}

Kupin Grigoriy Anatolievich Cand.Tech.Sci., RSCI SPIN-code: 1946-6756, kisp@kubannet.ru

Pershakova Tatiana Viktorovna

Dr.Sci.Tech., associate professor, RSCI SPIN-code 4342-6560, 7999997@inboxru

Gorlov Sergey Mikhailovich

Cand.Tech.Sci., assistant professor RSCI SPIN-code 5082-8400, gorlov76@list.ru

Victorova Elena Pavlovna

Doctor of Technical Sciences, professor

RSCI SPIN-code: 9599-4760, kisp@kubannet.ru

\author{
Matvienko Alina Nikolaevna \\ RSCI SPIN-code \\ 4564-8347, kisp@kubannet.ru
}

Velikanova Elena Vasilevna

RSCI SPIN-code: 9695-7292, kisp@kubannet.ru "Krasnodar Research Institute of Agricultural Products Storage and Processing” - branch of FSBSO "North-Caucasian Federal Scientific Center of Horticulture \& Viniculture”, Russia, 350072,

Krasnodar, st. Topolinaya alleya, 2

Technologies of fruits storing known at the present time, solving actual problems - slowing down biochemical processes, inhibiting ethylene synthesis, do not provide fully the preservation of quality of fruits due to not taking into consideration the peculiarities of microflora of fruits and microbiological processes, taking place during storage. Purpose of the research: investigation of influence of complex treatment of fruits with electromagnetic fields of extremely low frequency (ELF EMF) and the biopreparation "Vitaplan" on changing of losses of biologically active substances in the process of longterm storage. Objects of the research: apples of the Idared variety and pears of the Conference variety, regionalized in the Krasnodar region. Mass shares of the vitamin $\mathrm{C}$ and $\mathrm{P}$-active substances were measured 
хранения определяли массовую долю витамина С и Р-активных веществ. Обработка ЭМП КНЧ проводилась на экспериментальной установке. Фрукты подвергали воздействию электромагнитного поля с заданными параметрами. Комплексная обработка фруктов (яблок и груш) ЭМП КНЧ и биопрепаратом «Витаплан» перед закладкой на хранение позволяет в максимальной степени сохранить биологически активные вещества - витамин С и Рактивные вещества. Синергетический эффект, возникающий за счет комплексного воздействия электромагнитного поля и биопрепарата, позволяет сократить время обработки в электромагнитном поле

Ключевые слова: ФРУКТЫ, СПОСОБЫ ХРАНЕНИЯ, ОБРАБОТКА ПЕРЕД ХРАНЕНИЕМ, КАЧЕСТВО, БИОПРЕПАРАТЫ, ЭЛЕКТРОМАГНИТНЫЕ ПОЛЯ, БИОЛОГИЧЕСКИ АКТИВНЫЕ ВЕЩЕСТВА in the process of storing. ELF EMF treatment was conducted on an experimental installation. Fruits were exposed to the action of electromagnetic fields with specified parameters. Complex treatment of fruits (apples and pears) with ELF EMF and the biopreparation "Vitaplan" before dispatching for storage allows preserving the biologically active substances the vitamin $\mathrm{C}$ and $\mathrm{P}$-active substances - to the maximum degree. Synergetic effect, appearing due to the complex action of electromagnetic field and the bio-preparation, allows decreasing the processing time in the electromagnetic field

Keywords: FRUIT, BIO-PREPARATIONS,

STORAGE OF PLANT MATERIALS, ELECTROMAGNETIC FIELDS, BIOLOGICALLY ACTIVE SUBSTANCES

Doi: 10.21515/1990-4665-132-087

Свежие фрукты, в частности яблоки и груши, являясь ценнейшим продуктом питания, должны быть доступны для потребления круглогодично. В связи с этим, актуальны исследования по обеспечению их эффективного длительного хранения.

Традиционно длительное хранение фруктов осуществляют в охлаждаемых хранилищах. Кроме обычной атмосферы в хранилищах может использоваться регулируемая или модифицированная газовая среда. При этом, состав среды дифференцируется в зависимости от зоны произрастания, сорта и агротехнических приёмов [1-3].

Использование модифицированной среды обычно сочетается с приемами, обеспечивающими ингибирование процессов биосинтеза этилена и дыхания. Так, например, широко используется препарат «Фитомаг» (соединение 1-метилцикнопропена), обеспечивая замедление процессов послеуборочного созревания фруктов [4,5].

Известные в настоящее время технологии, решая актуальные задачи замедления биохимических процессов и ингибирования синтеза этилена, к сожалению не обеспечивают в полной мере сохранение качества фруктов в http://ej.kubagro.ru/2017/08/pdf/87.pdf 
процессе хранения в связи с тем, что не учитывают особенности микрофлоры находящейся на поверхности и микробиологических процессов, протекающих при хранении.

В то же время, имеется опыт применения биопрепаратов, конкурирующих с фитопатогенными микроорганизмами и подавляющих их развитие, не оказывающих угнетающего действия на естественную устойчивость фруктов, а также позволяющих обеспечить сохранение их качества и количества [6,7].

Кроме того, проведенные ранее исследования позволили установить эффективность обработки фруктов (яблок и груш) электромагнитными полями крайне низких частот, позволяющей снизить микробиальную обсемененность их поверхности, а также снизить потери биологически активных веществ. Были определены режимы обработки фруктов электромагнитными полями крайне низких частот: для яблок: частота - 22 Гц, сила тока - 10 А, продолжительность обработки - 40 минут; для груш: частота - 26 Гц, сила тока - 5 А, продолжительность обработки - 50 минут $[8,9]$.

Однако, значительное время обработки (40-50 минут) является существенным недостатком, препятствующим созданию компактных и высокопроизводительных промышленных установок, для обработки фруктов перед хранением. В связи с этим, представляли интерес исследования, позволяющие сократить время обработки за счет комплексной обработки фруктов электромагнитными полями крайне низких частот (ЭМП КНЧ) и биопрепаратами. Как один из аспектов, было изучено влияние такой обработки на сохранность биологически активных веществ, содержащихся в фруктах в процессе хранения.

Цель исследования: изучение влияния комплексной обработки фруктов ЭМП КНЧ и биопрепаратом «Витаплан» на изменение потерь биологически активных веществ в процессе их длительного хранения. 


\section{Объекты и методы}

Объекты исследования: яблоки сорта Айдаред и груши сорта Конференция, районированные в Краснодарском крае, урожая 2016 года.

В процессе хранения определяли массовую долю витамина С - по ГОСТ 24556-89 [10] и массовую долю Р-активных веществ в соответствии с методикой, приведенной в работе [11].

В качестве биопрепарата использовали водный раствор биопрепарата «Витаплан» [12]. Обработка электромагнитными полями крайне низких частот проводилась на экспериментальной установке. Фрукты подвергали воздействию электромагнитного поля с заданными параметрами [13].

В качестве контрольных образцов использовали фрукты, не подвергавшиеся обработке ЭМП КНЧ и раствором биопрепарата.

Фрукты перед закладкой на хранение обрабатывались по следующим схемам.

Яблоки. Образец № 1. І этап - обработка ЭМП КНЧ с параметрами частота - 22 Гц, сила тока - 10 А в течение 40 минут.

Образец № 2. І этап - обработка ЭМП КНЧ с параметрами - 30 Гц - 15 А в течение 5 минут; II этап - обработка водным раствором биопрепарата «Витаплан» с концентрацией биоагента $10^{6}$ КОЕ/г (расход - 1 мл на 100 г фруктов)

Груши. Образец № 1. I этап - обработка ЭМП КНЧ с параметрами частота - 26 Гц, сила тока -5 А в течение 50 минут.

Образец № 2. І этап - обработка ЭМП КНЧ с параметрами - 26 Гц - 10 А в течение 5 минут; II этап - обработка водным раствором биопрепарата «Витаплан» с концентрацией биоагента $10^{6}$ КОЕ/г (расход - 1 мл на 100 г фруктов).

Яблоки хранили в течение 7 месяцев, а груши - в течение 6 месяцев. Температура хранения: яблоки сорта Айдаред $-\left(+2^{\circ} \mathrm{C}\right) ;$ груши http://ej.kubagro.ru/2017/08/pdf/87.pdf 
сорта Конференция $-\left(0^{\circ} \mathrm{C}\right)$. Относительная влажность воздуха $-90 \%$. Отбор проб поводили 1 раз в месяц.

\section{Результаты исследования и их обсуждение.}

Данные по влиянию комплексной обработки яблок ЭМП КНЧ и биопрепаратом «Витаплан» на потери витамина С в процессе хранения приведены на рисунке 1.

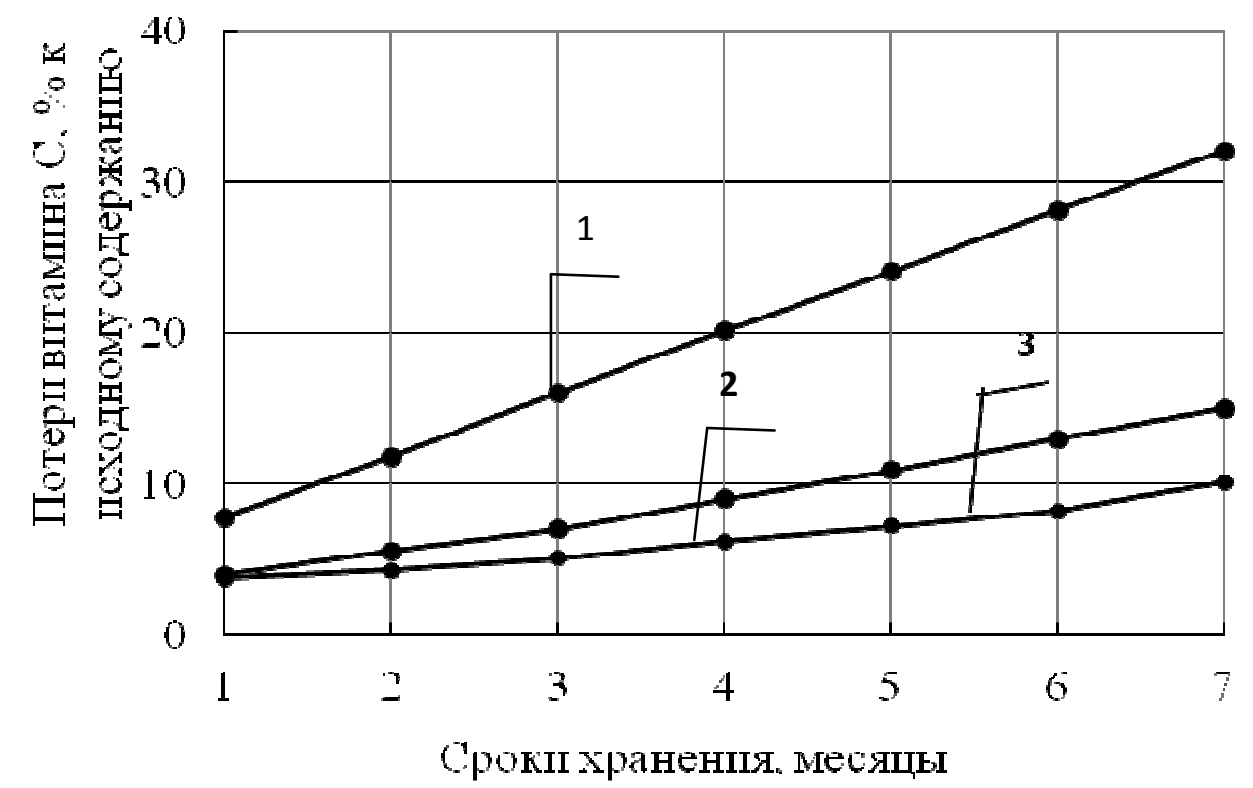

Рисунок 1 - Влияние предварительной обработки яблок сорта Айдаред в ЭМП КНЧ и биопрепаратом «Витаплан» на потери витамина С в процессе хранения:

1 - контроль; 2 - образец №1 обработка ЭМП КНЧ;

3- образец №2 - обработка ЭМП КНЧ и биопрепаратом

Из приведенных на рисунке данных видно, что к концу срока хранения снижение потерь витамина $\mathrm{C}$ по сравнению с контрольным (необработанным) образцом составляло: для яблок, предварительно обработанных перед закладкой на хранение ЭМП КНЧ и биопрепаратом 21,9\%, обработанных только ЭМП КНЧ - 17,0\%. 
На рисунке 2 приведены данные по влиянию комплексной обработки груш ЭМП КНЧ и биопрепаратом «Витаплан» на потери витамина С в процессе хранения.

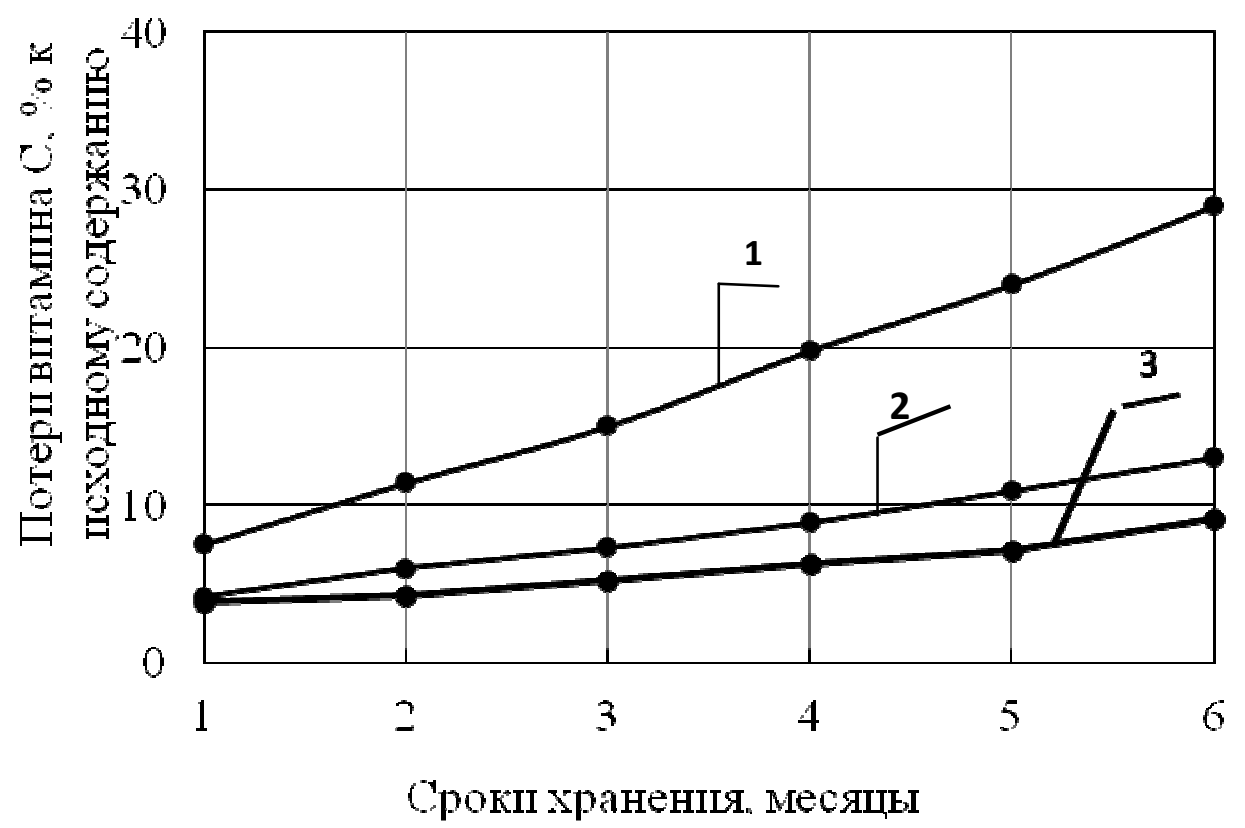

Рисунок 2 - Влияние предварительной обработки груш сорта Конференция в ЭМП КНЧ и биопрепаратом «Витаплан» на потери витамина С в процессе хранения:

1 - контроль; 2 - образец №1 обработка ЭМП КНЧ;

3 - образец № 2 - обработка ЭМП КНЧ и биопрепаратом

Данные, приведенные на рисунке 2, показывают, что к концу срока хранения снижение потерь витамина $\mathrm{C}$, по сравнению с контрольным (необработанным) образцом составляло: для груш, предварительно обработанных перед закладкой на хранение ЭМП КНЧ и биопрепаратом 19,9\%, обработанных только ЭМП КНЧ - 16,0 \%.

На рисунке 3 - приведены данные по влиянию обработки фруктов ЭМП КНЧ и биопрепаратом на потери $\mathrm{P}$ - активных веществ в процессе хранения. 


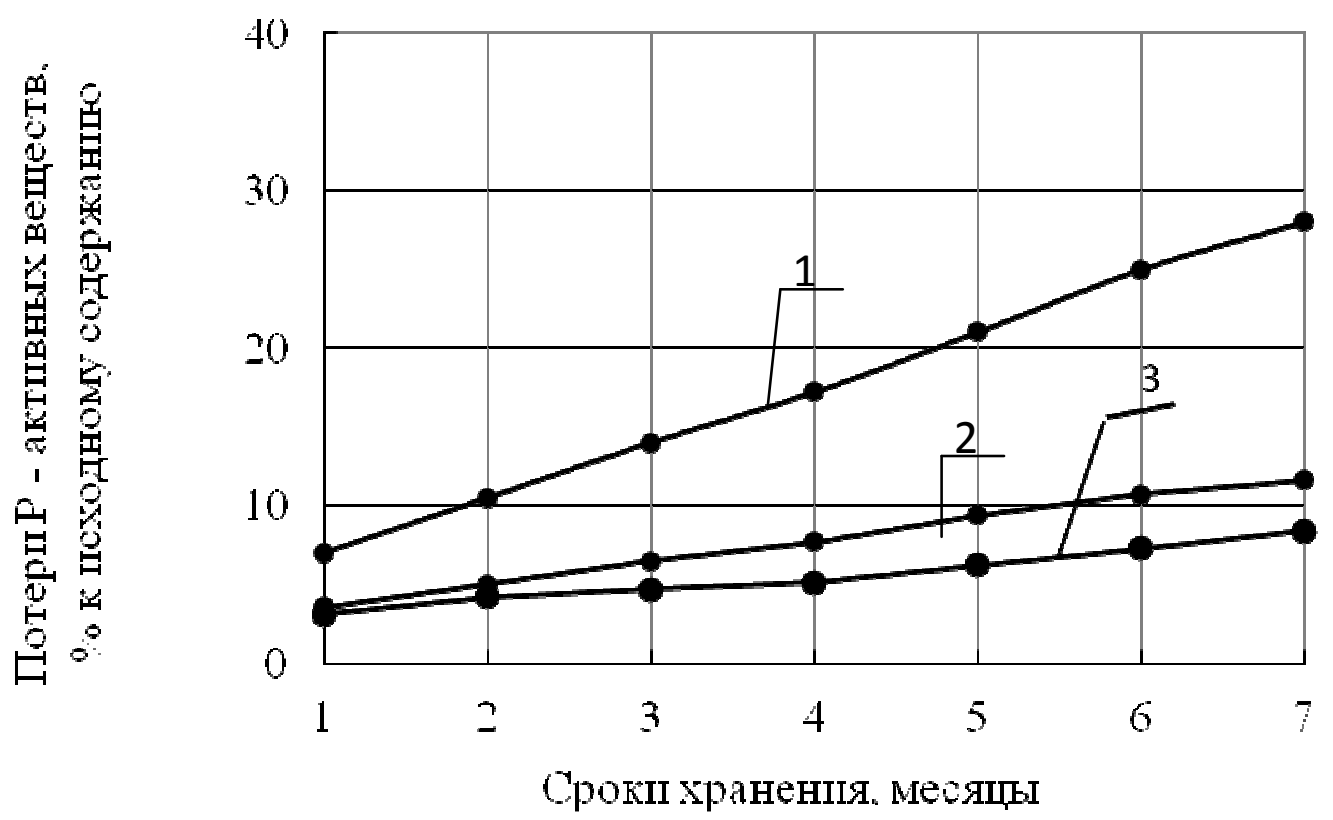

Рисунок 3 - Влияние предварительной обработки яблок сорта Айдаред в ЭМП КНЧ и биопрепаратом «Витаплан» на потери P - активных веществ в процессе хранения:

1 - контроль; 2 - образец №1 обработка ЭМП КНЧ;

3 - образец № 2 - обработка ЭМП КНЧ и биопрепаратом

Анализируя данные приведенные на рисунке 3 можно сделать вывод о том, что потери Р-активных веществ по сравнению с контрольным (необработанным) образцом через 7 месяцев хранения составили: для предварительно обработанных перед закладкой на хранение ЭМП КНЧ и биопрепаратом яблок - 26,4\%; только ЭМП КНЧ - 19,6 \%. 


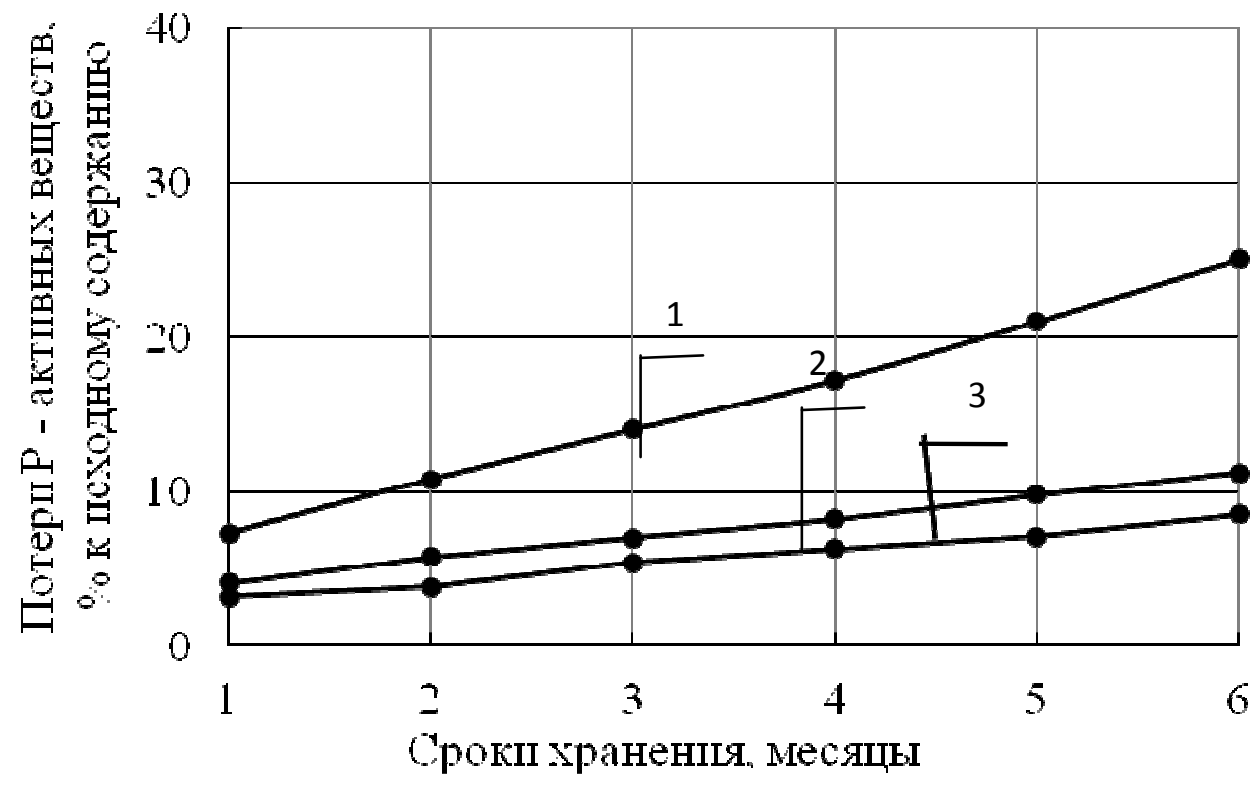

Рисунок 4 - Влияние предварительной обработки груш сорта

Конференция в ЭМП КНЧ и биопрепаратам «Витаплан» на потери Р - активных веществ в процессе хранения:

1 - контроль; 2 - образец №1 обработка ЭМП КНЧ;

3 - образец № 2 - обработка ЭМП КНЧ и биопрепаратом

Представленные на рисунке данные позволяют сделать вывод сто через 7 месяцев хранения груш, снижение потерь Р-активных веществ по сравнению с контрольным (необработанным) образцом составляло: для предварительно обработанных перед закладкой на хранение ЭМП КНЧ и биопрепаратом фруктов - 16,5\%; только ЭМП КНЧ - 13,8 \%.

Таким образом установлено, что комплексная обработка фруктов (яблок и груш) перед закладкой на хранение в ЭМП КНЧ и биопрепаратом «Витаплан» позволяет сократить время обработки перед закладкой на хранение и при этом в максимальной степени сохранить в продукте биологически активные вещества - витамин $\mathrm{C}$ и $\mathrm{P}$ - активные вещества - за счет эффективного ингибирования нежелательных процессов, вызываемых развитием патогенной микрофлоры и http://ej.kubagro.ru/2017/08/pdf/87.pdf 


\section{Выводы}

1.Комплексная обработка фруктов (яблок и груш) в ЭМП КНЧ и биопрепаратом «Витаплан» перед закладкой на хранение позволяет в максимальной степени сохранить в продукте биологически активные вещества - витамин С и Р-активные вещества.

2.Синергетический эффект, возникающий за счет комплексного воздействия электромагнитного поля и биопрепарата, позволяет сократить время обработки в электромагнитном поле, что делает возможным разработку компактных промышленных установок для обработки фруктов перед хранением.

\section{Список литературы}

1.Причко Т.Г. Оптимизация режимов и способов послеуборочной обработки и хранения яблок Кубани с учетом биохимических особенно-стей., Автореф. дис. канд.техн. наук. Краснодар, 1990. -24c.

2.Причко Т.Г. Сорта яблок с высокой биологически обусловленной лежкостью. // Научные основы устойчивого садоводства в России. Мичуринск. -1999. C.219-221.

3.Гудковский, В.А. Методы прогноза лёжкости плодов (рекомендации)/ В.А. Гудковский. -М.: Агропромиздат, 1990. 33 с.

4.Гудковский, В.А. Комплексная система мер борьбы с потерями фруктов и сохранения их качества при хранении и доведении до потребителя / В.А. Гудковский. Алма-Ата, 1985.- 83с.

5.Гудковский, В.А. Система сокращения потерь и сохранения качества плодов и винограда при хранении: Методические рекомендации / В.А. Гудковский. Мичуринск, 1990. - 120 с.

6.Першакова, Т.В. Способы обеспечения стабильного качества растительного сырья в процессе хранения с применением биопрепаратов [Электронный ресурс] / Т.В. Першакова, В.В. Лисовой, Г.А. Купин, Е.П. Викторова, Е.Ю. Панасенко // Политематический сетевой электронный научный журнал Кубанского государственного аграрного университета (Научный журнал КубГАУ). - 2016. - № 03 (117). - URL: http://ej.kubagro.ru/2016/03/pdf/33.pdf (дата обращения: 11.10.2017).

7. Перспективы применения биопрепаратов при хранении фруктов / В.Н. Алёшин, Г.А. Купин, Т.В. Першакова, Д.В. Кабалина // Сборник материалов конгресса «Наука, питание и здоровье».- г. Минск, 8-9 июня 2017 г. - С. 452 - 459.

8.Лисовой, В.В. Исследование влияния электромагнитных полей на изменение микробиальной обсемененности фруктов в процессе хранения / В.В. Лисовой, Т.В. Першакова, Е.П. Викторова, Г.А. Купин, В.Н. Алёшин, Л.В. Михайлюта // Политематический сетевой электронный научный журнал Кубанского государственного аграрного университета (Научный журнал КубГАУ) 
[Электронный http://ej.kubagro.ru/2017/02/pdf/59.pdf (дата обращения: 11.10.2017).

9.Першакова, Т.В. Исследование влияния электромагнитного поля на изменение микробиальной обсемененности растительного сырья в процессе хранения /Т.В. Першакова, В.В. Лисовой, Г.А. Купин, Л.В. Михайлюта, Е.Ю. Панасенко, Е.П. Викторова// Успехи современного естествознания. - 2016. - № 5. C. 74-78; URL: http://natural-sciences.ru/ru/article/view?id=35901 (дата обращения: 11.10.2017).

10.ГОСТ 24556-89. Продукты переработки фруктов и овощей. Методы определения витамина С. - Введ. 01.01.1990. - М.: Изд-во стандартов, 2003. - 11 с.

11.Запрометов, М.Н. Основы биохимии фенольных соединений. [Текст]: Учебное пособие для биологических специальностей университетов / М.Н. Запрометов - М.: «Высшая школа», 1974. - 75 с.

12.Витаплан СП [Электронный pecypc] - URL: http://bioprotection.ru/new/preparations/vitaplan-sp-100-g.html (дата обращения 11.10.2017).

13.Купин Г. А., Исследование влияния электромагнитного поля на изменение микробиальной обсеменности корнеплодов моркови в процессе хранения./ Г. А Купин., Е. П Викторова., В. Н Алёшин., Л. В. Михайлюта //Вестник АПК Ставрополья - 2015. № 4(20), - С. 231-236.

\section{References}

1.Prichko T.G. Optimizacija rezhimov i sposobov posleuborochnoj obrabotki i hranenija jablok Kubani s uchetom biohimicheskih osobenno-stej., Avtoref. dis. kand.tehn. nauk. Krasnodar, 1990. -24s.

2.Prichko T.G. Sorta jablok s vysokoj biologicheski obuslovlennoj lezhko-st'ju. // Nauchnye osnovy ustojchivogo sadovodstva v Rossii. Michurinsk. -1999. -S.219-221.

3.Gudkovskij, V.A. Metody prognoza ljozhkosti plodov (rekomendacii)/ V.A. Gudkovskij. -M.: Agropromizdat, 1990. 33 s.

4.Gudkovskij, V.A. Kompleksnaja sistema mer bor'by s poterjami fruktov i sohranenija ih kachestva pri hranenii i dovedenii do potrebitelja / V.A. Gudkovskij. AlmaAta, 1985.- 83s.

5.Gudkovskij, V.A. Sistema sokrashhenija poter' i sohranenija kachestva plodov i vinograda pri hranenii: Metodicheskie rekomendacii / V.A. Gudkovskij. Michurinsk, 1990. - $120 \mathrm{~s}$.

6.Pershakova, T.V. Sposoby obespechenija stabil'nogo kachestva rastitel'nogo syr'ja $\mathrm{v}$ processe hranenija $\mathrm{s}$ primeneniem biopreparatov [Jelektronnyj resurs] / T.V. Pershakova, V.V. Lisovoj, G.A. Kupin, E.P. Viktorova, E.Ju. Panasenko // Politematicheskij setevoj jelektronnyj nauchnyj zhurnal Kubanskogo gosudarstvennogo agrarnogo universiteta (Nauchnyj zhurnal KubGAU). - 2016. - № 03 (117). - URL: http://ej.kubagro.ru/2016/03/pdf/33.pdf (data obrashhenija: 11.10.2017).

7. Perspektivy primenenija biopreparatov pri hranenii fruktov / V.N. Aljoshin, G.A. Kupin, T.V. Pershakova, D.V. Kabalina // Sbornik materialov kongressa «Nauka, pitanie i zdorov'e».- g. Minsk, 8-9 ijunja 2017 g. - S. 452 - 459.

8.Lisovoj, V.V. Issledovanie vlijanija jelektromagnitnyh polej na izmenenie mikrobial'noj obsemenennosti fruktov $\mathrm{v}$ processe hranenija / V.V. Lisovoj, T.V. Pershakova, E.P. Viktorova, G.A. Kupin, V.N. Aljoshin, L.V. Mihajljuta // Politematicheskij setevoj jelektronnyj nauchnyj zhurnal Kubanskogo gosudarstvennogo 
agrarnogo universiteta (Nauchnyj zhurnal KubGAU) [Jelektronnyj resurs]. - 2017. - № 126 (02). URL: http://ej.kubagro.ru/2017/02/pdf/59.pdf (data obrashhenija: 11.10.2017).

9.Pershakova, T.V. Issledovanie vlijanija jelektromagnitnogo polja na izmenenie mikrobial'noj obsemenennosti rastitel'nogo syr'ja v processe hranenija /T.V. Pershakova, V.V. Lisovoj, G.A. Kupin, L.V. Mihajljuta, E.Ju. Panasenko, E.P. Viktorova// Uspehi sovremennogo estestvoznanija. - 2016. - № 5. - S. 74-78; URL: http://naturalsciences.ru/ru/article/view?id=35901 (data obrashhenija: 11.10.2017).

10.GOST 24556-89. Produkty pererabotki fruktov i ovoshhej. Metody opredelenija vitamina C. - Vved. 01.01.1990. - M.: Izd-vo standartov, 2003. - 11 s.

11.Zaprometov, M.N. Osnovy biohimii fenol'nyh soedinenij. [Tekst]: Uchebnoe posobie dlja biologicheskih special'nostej universitetov / M.N. Zaprometov - M.: «Vysshaja shkola», 1974. - $75 \mathrm{~s}$.

12.Vitaplan SP [Jelektronnyj resurs] http://bioprotection.ru/new/preparations/vitaplan-sp-100-g.html (data obrashhenija 11.10.2017).

13.Kupin G. A., Issledovanie vlijanija jelektromagnitnogo polja na izmenenie mikrobial'noj obsemennosti korneplodov morkovi v processe hranenija./ G. A Kupin., E. P Viktorova., V. N Aljoshin., L. V. Mihajljuta //Vestnik APK Stavropol'ja - 2015. № 4(20), - S. 231-236. 